\title{
TUNING RANGE OF THE BOOSTER
}

\section{BOOSTER TECHNICAL NOTE \\ NO. 168}

\author{
S. Y. LEE
}

JUNE 19, 1990

\section{ALTERNATING GRADIENT SYNCHROTRON DEPARTMENT BROOKHAVEN NATIONAL LABORATORY \\ UPTON, NEW YORK 11973}




\title{
TUNING RANGE OF THE BOOSTER
}

\author{
S. Y. LEE
}

\section{$\underline{\text { Abstract }}$}

Due to the requirement of fast ramping $(7.5 \mathrm{~Hz})$ and tight tracking between dipole and quadrupole, a single power supply was initially conceived for the dipole and quadrupoles. This paper studies the flexibility of the present power supply configuration with the single turn $700 \mathrm{~A}$ trim quadrupoles.

\section{Int roduction}

A single power supply will be initially used in the Booster operation for the dipole and quadrupoles. Based on the recently measured data: ${ }^{1}$

$$
\begin{aligned}
& \mathrm{L}_{\mathrm{DIP}}=2.42 \mathrm{~m} \\
& \mathrm{~B} / \mathrm{I}=2.4356 \text { Gauss/Amp } \\
& \mathrm{L}_{\mathrm{QD}}=0.5064 \mathrm{~m} \\
& \mathrm{~L}_{\mathrm{QF}}=0.4937 \\
& \mathrm{~B} / \mathrm{I}=2.4396 \text { Gauss/Amp }
\end{aligned}
$$

Operational conditions of the Booster can be calculated. Note that the effective length of the Booster may change due to more magnet data accumulation. But the change of the magnet data only affects the working point. The calculation and conclusion of this paper will remain valid. Since the Booster quadrupole has a one turn trim coil winding with the current capability of $700 \mathrm{~A}$ or higher, the turnability of the machine can be studied. This report tries to evaluate the machine operational range and its implications. Suggestion for future improvement will be discussed.

\section{Operational Condition of the Booster}

Table 1 shows the current in the main quadrupole power supply and the percentage in strength of the trim power supply at $700 \mathrm{~A}$. We observe that indeed the trim quadrupole winding offers a great turnability for the machine at the low energies. For proton, Fig. 1 shows the operational region at various kinetic energies. At the extraction energy of $1.5 \mathrm{GeV}$, the operational range will shrink to small diamond between tunes of 4.25 and 4.9 around the diagonal line.

At $0.5 \mathrm{GeV}$, we can study the machine stability in the complete tune space including $\mid \mathrm{Q}_{\mathrm{x}}{ }^{-}$ $\mathrm{Q}, 1 \geq 1$. Since the Booster is a machine with 6 fold symmetry, the operational range would be between 3 and 6 , the present configuration is indeed versatile. 


\section{Table 1}

\begin{tabular}{|l|c|c|c|}
\hline \multicolumn{1}{|c|}{ Bp (Tm) } & $\begin{array}{c}5 \text { Turn } \\
\text { I (main)(A) }\end{array}$ & $\begin{array}{c}1 \text { Turn } \\
\text { I (trim) }\end{array}$ & of Percentage Trim. \\
\hline$\rho: 2.15$ & 640 & 700 & $22 \%$ \\
\hline$\rho: 7.50$ & 2250 & 700 & $6.2 \%$ \\
\hline Au: 0.89 & 250 & 700 & $56 \%$ \\
\hline Au: 17.5 & 5700 & 700 & $2.5 \%$ \\
\hline
\end{tabular}

However, it is interesting to point out that the separate buses of power supply for dipole, focusing and defocusing quadrupoles can provide wider range of tuning. Since the Booster performance can be well studied at $0.5 \mathrm{GeV}$ in the entire region of the tune space, there is no compelling reason for the separate power supply for the quadrupoles. However, separate busses for QF and QD's offer us a future flexibility for moving the working point outside the diagonal line by adding bypass power supplies. There is no theoretical reason for the preference of a specific working point except to watch the possible systematic resonance lines shown in Fig. 1 up to the fourth order. Therefore, $\mathrm{Q}_{\mathrm{x}} \approx \mathrm{Q}_{\mathrm{y}} \approx 4.8$ or $\mathrm{Q}_{\mathrm{x}} \approx 4.8, \mathrm{Q}_{\mathrm{y}} \approx 3.8$, or $\mathrm{Q}_{\mathrm{y}} \approx 4.8, \mathrm{Q}_{\mathrm{x}} \approx$ 3.8 are all possible working points. Careful machine study can map out the advantage and disadvantages of each working point. Fig. 1 shows clearly that all the viable operational region can be achieved up to $0.8 \mathrm{GeV}$ with a single power supply with $700 \mathrm{~A}$ single turn trim coil. Once the performance of the Booster is well-understood, the desirability of extra power supplies can be evaluated. At this point, the flexibility of the separate busses will be valuable if the Booster would perform better at $\mathrm{Q}_{\mathrm{x}}=3.8$ and $\mathrm{Q}_{\mathrm{y}}=4.8$. This may turn out to be true for the heavy ion operation, where the horizontal orbit will be about $1.5^{\prime \prime}$ from the center of the quadrupole due to orbit bump and 3" from the center of the quadrupole F6 due to the kicker. The least saturation for the focusing quadruple will be important in the orbit manipulation. Figure 2 shows the similar operational range for heavy ion at $\mathrm{B} \rho=17.6 \mathrm{Tm}$ with a single power supply.

\section{Discussions and Suggestions}

A single power supply option in the Booster operation will limit the operation to the diagonal line $Q_{x} \approx Q_{y}$ tune space. The analysis shows that the Booster operation is indeed versatile at $B \rho \leq 4 \mathrm{Tm}$. Careful machine physics studies at $B \rho \leq 4 \mathrm{Tm}$ will give us enough information on the optimal working point. If the optimal working point turn out to be $\left|Q_{x}-Q_{y}\right|$ $\approx 1$, the separate buses for the dipole QF's and QD's will be extremely useful in the future upgrade. Thus the Booster shall perform well for a single power supply. To obtain the flexibility, three separate buses system is can be explored for future upgrade.

\section{References:}

1. E. Bleser, private communication. 


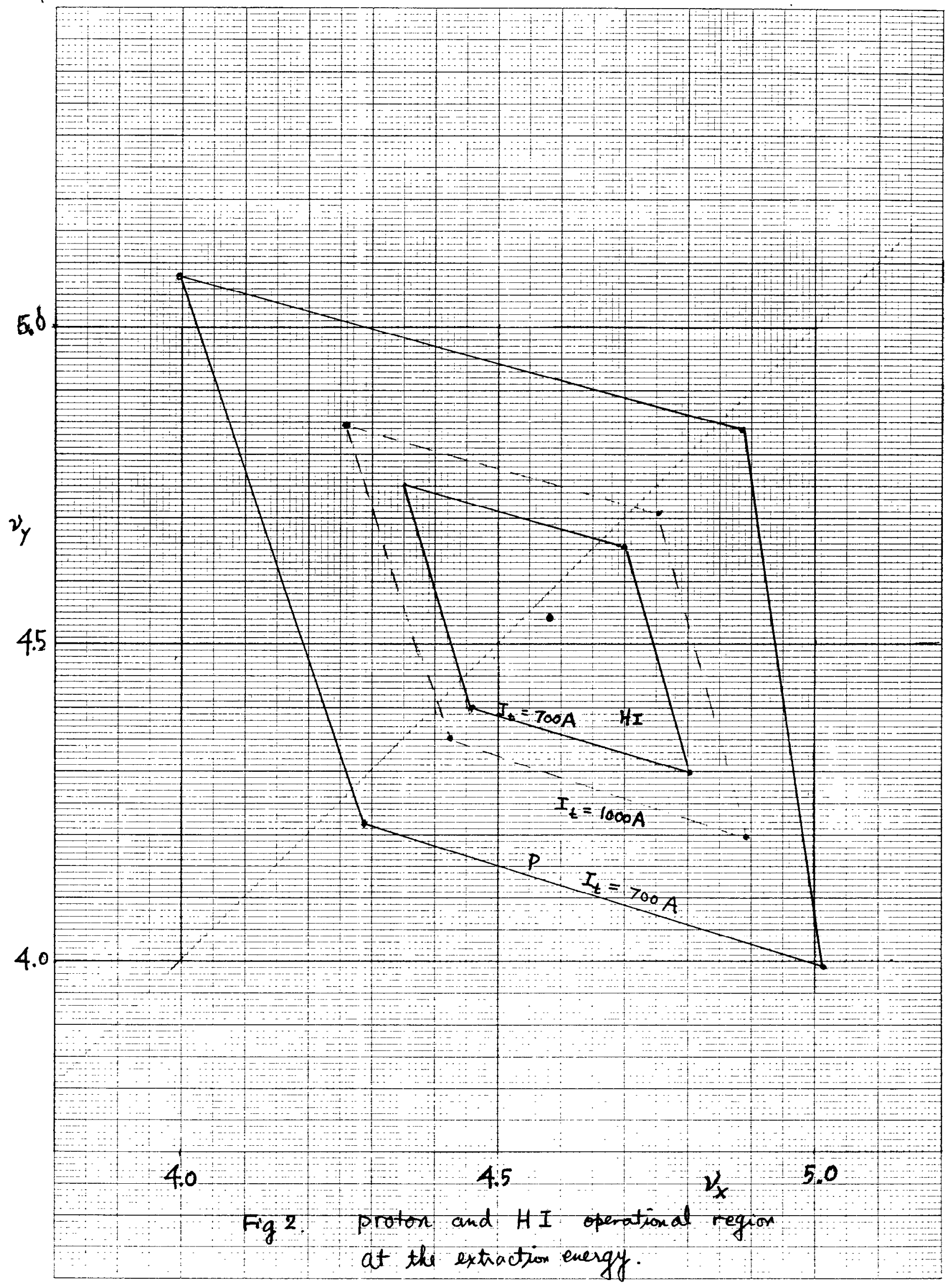

